Precision Polyketones by Ring-Opening Metathesis Polymerization: The Effects of Regular and Irregular Ketone Spacing

Kyle J. Arrington, Clifton B. Murray, Emily C. Smith, Hervé Marand, and John B. Matson

Department of Chemistry and Macromolecules and Interfaces Institute, Virginia Tech, Blacksburg, Virginia 24061, United States.

Email: jbmatson@vt.edu, hmarand@vt.edu

Table of Contents:

ROMP Kinetic Plots: Page S2

ROMP GPC Traces: Pages S3-S4

Cycloheptene Monomer and Polymer NMR spectra, IR spectra, and WAXD: Pages S5-S13

Cyclooctene Monomer and Polymer NMR spectra, IR spectra, and WAXD: Pages S14-S22

Reference: Page S22 


\section{Kinetics Plots:}

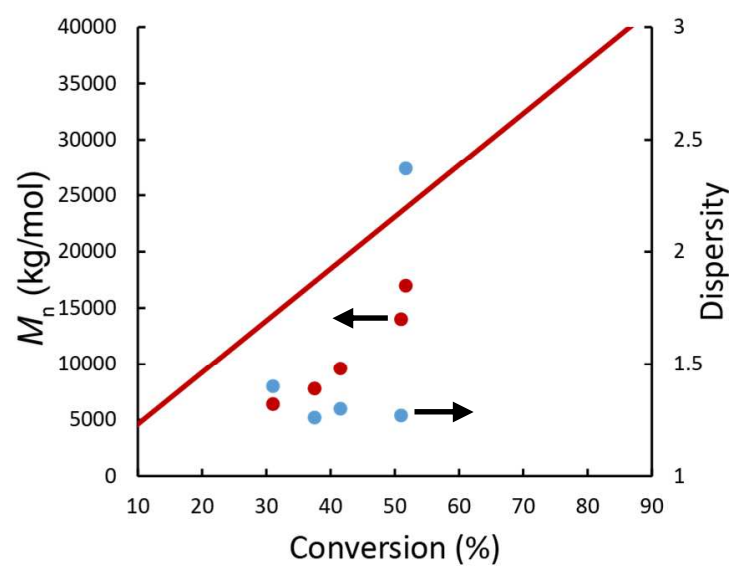

Figure S1. Kinetics plot of $M_{n}$ and $Đ$ vs. conversion for ROMP of monomer 7.4 at $25^{\circ} \mathrm{C}$.

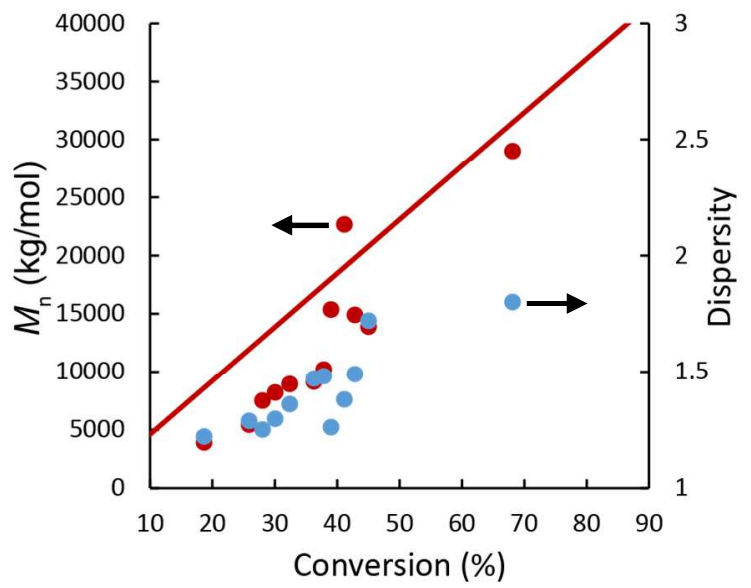

Figure S2. Kinetics plot of $M_{\mathrm{n}}$ and $Ð$ vs. conversion for ROMP of monomer 7.4 at $20^{\circ} \mathrm{C}$.

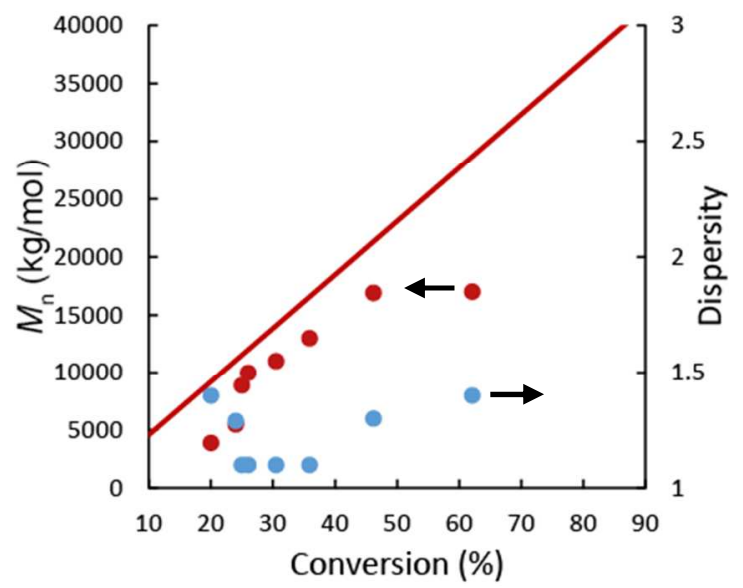

Figure S3. Kinetics plot of $M_{n}$ and $Đ$ vs. conversion for ROMP of monomer 7.4 at $10^{\circ} \mathrm{C}$. 
GPC Traces:

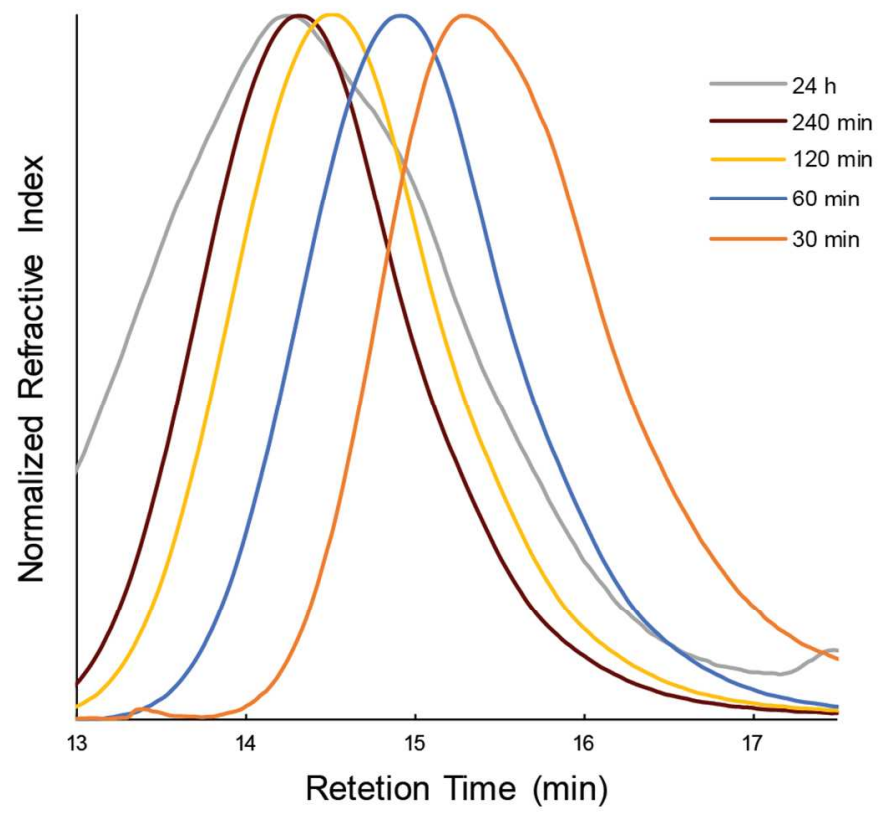

Figure S4: GPC traces for the kinetics study of monomer 7.4 using $\mathrm{G} 1$ at $25^{\circ} \mathrm{C}$.

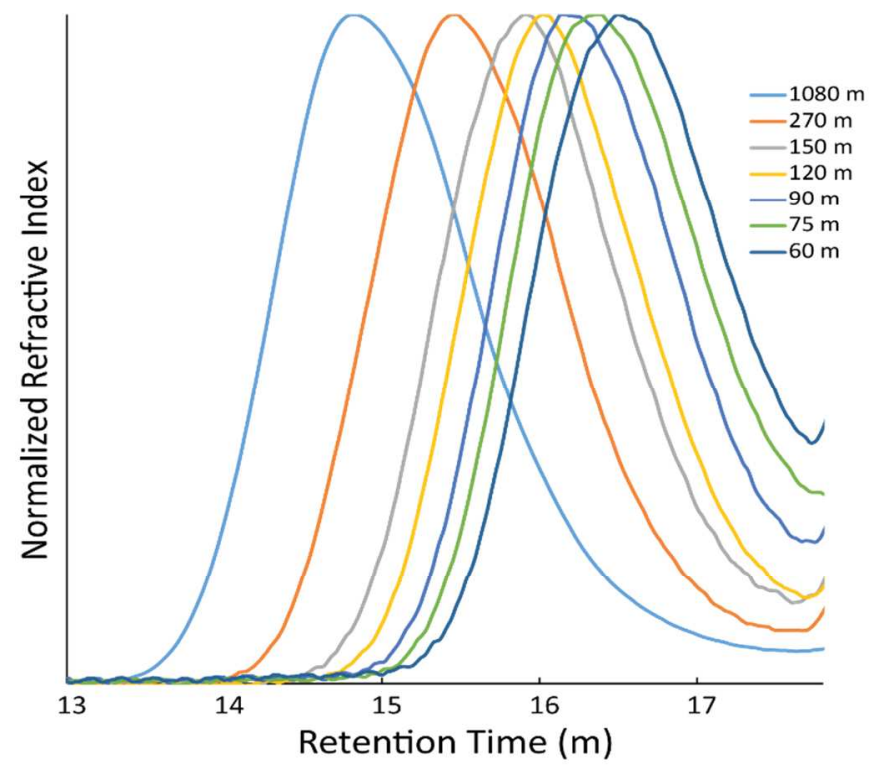

Figure S5: GPC traces for the kinetics study of monomer 7.4 at $20^{\circ} \mathrm{C}$. 


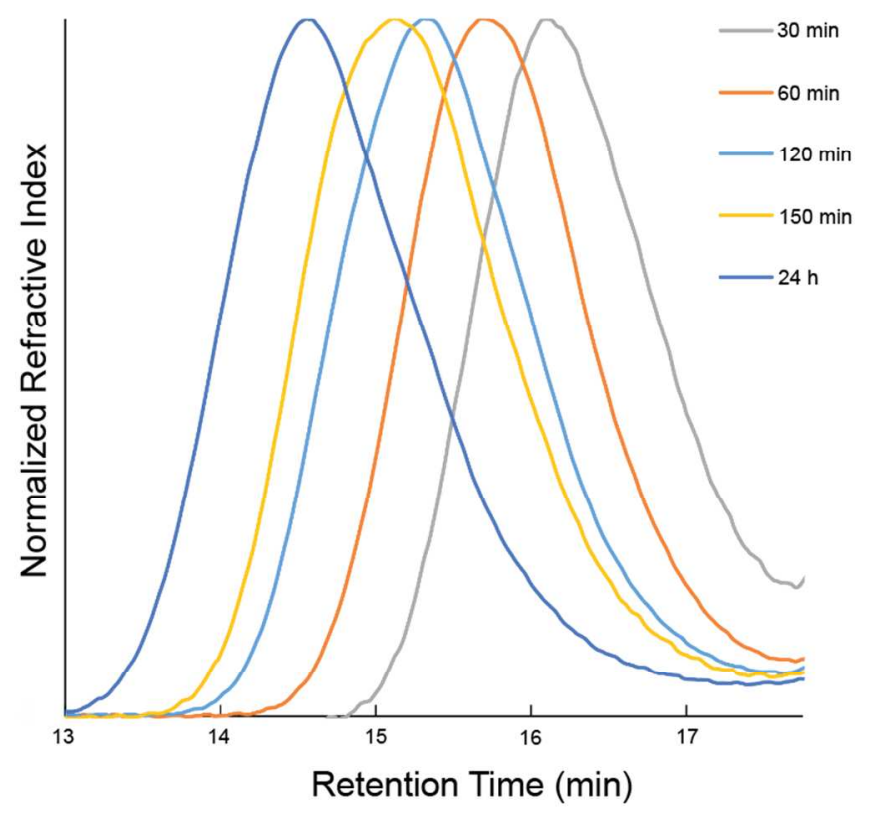

Figure S6: GPC traces for the kinetic ROMP study of monomer 7.4 at $15^{\circ} \mathrm{C}$.

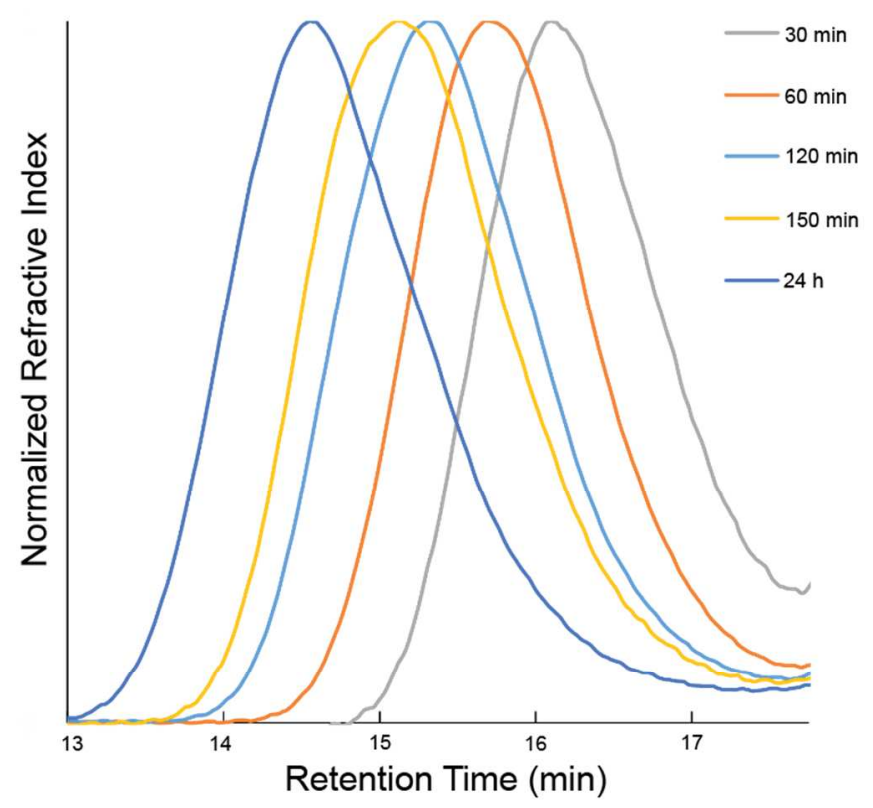

Figure S7: GPC traces for the kinetic ROMP study of monomer 7.4 at $10^{\circ} \mathrm{C}$. 
NMR Spectra
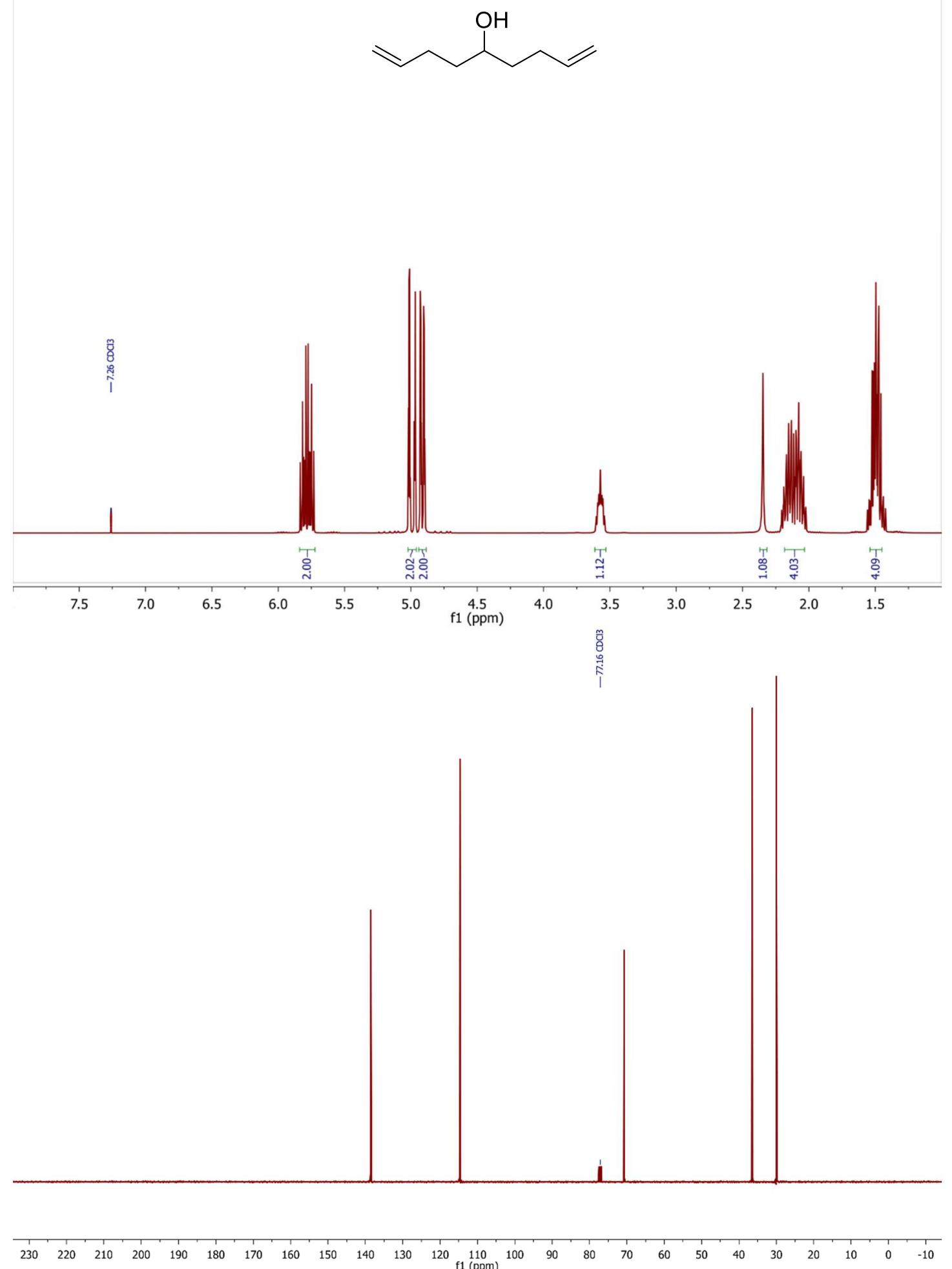

Figure S8: 7.1 NMR Spectra 

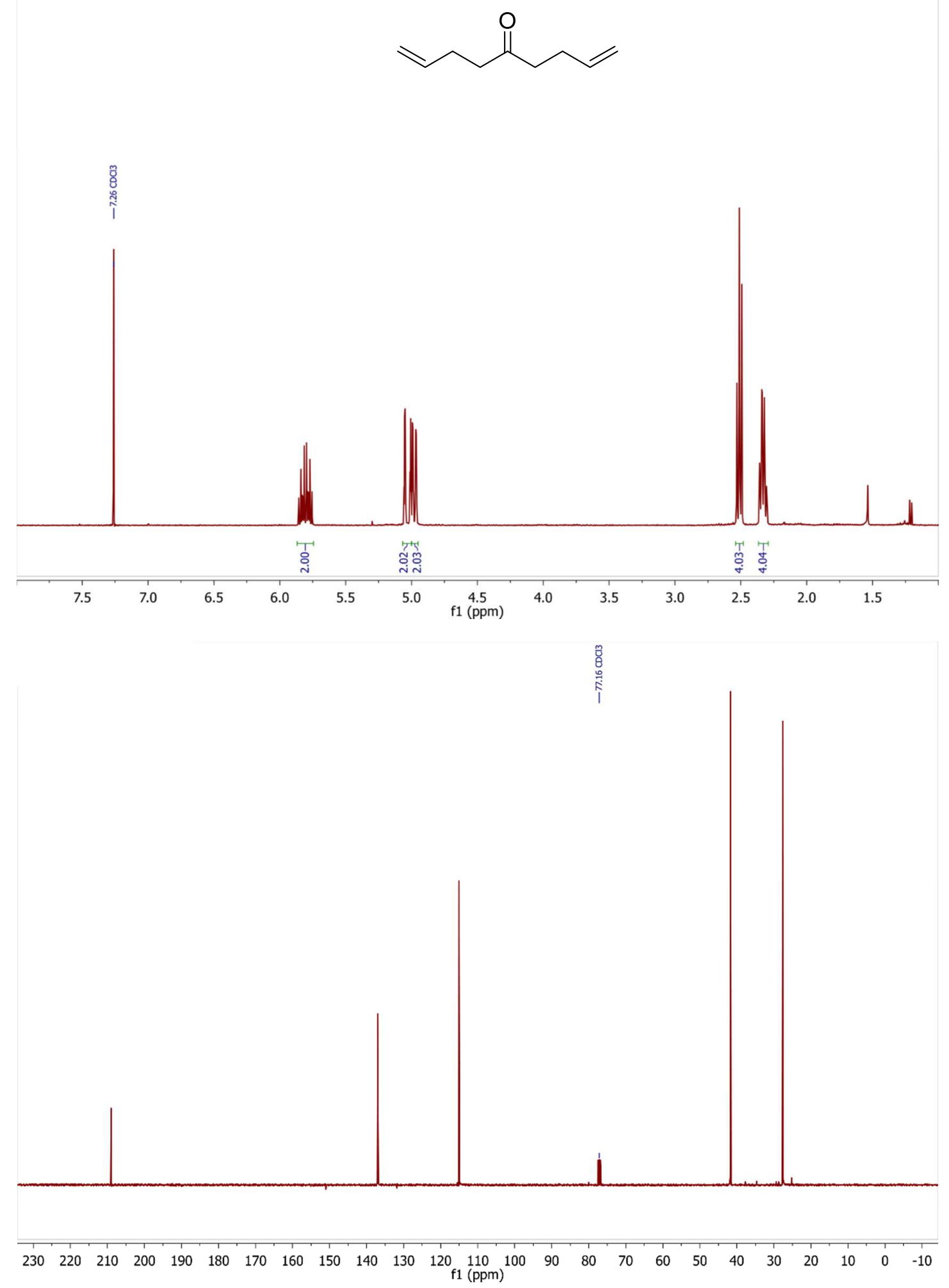

Figure S9: 7.2 NMR Spectra 

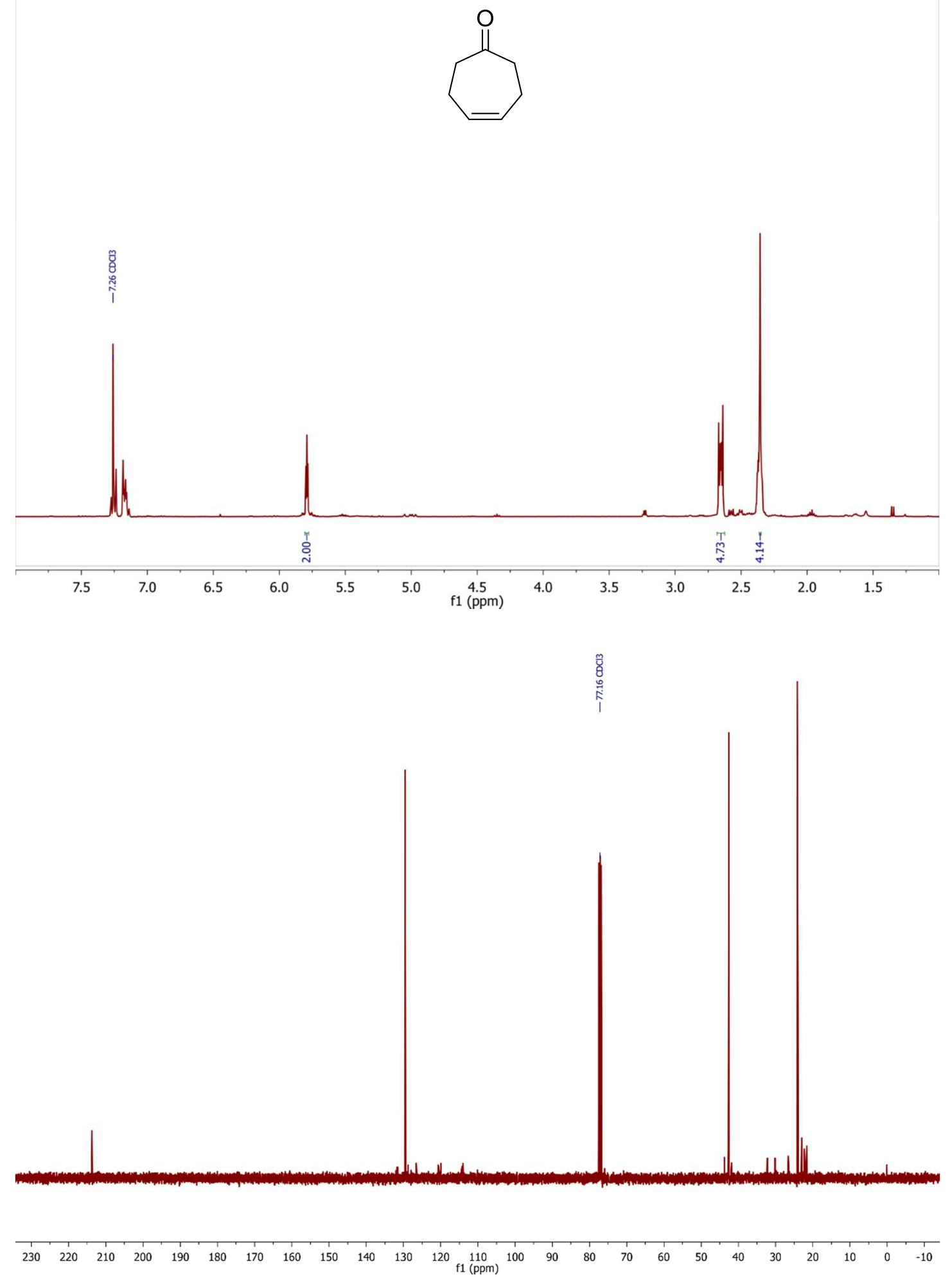

Figure S10: 7.3 NMR Spectra 

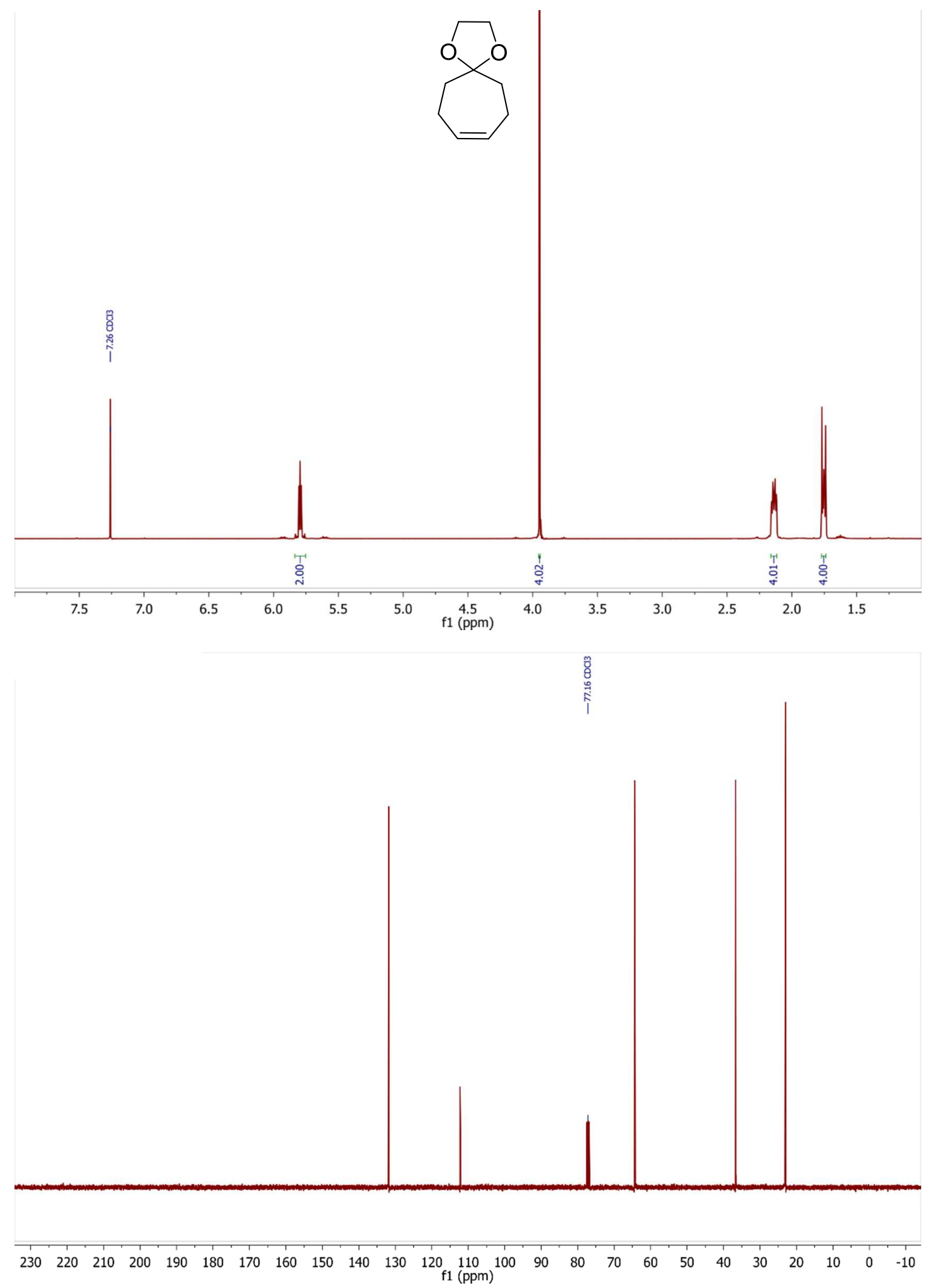

Figure S11: 7.4 NMR Spectra 

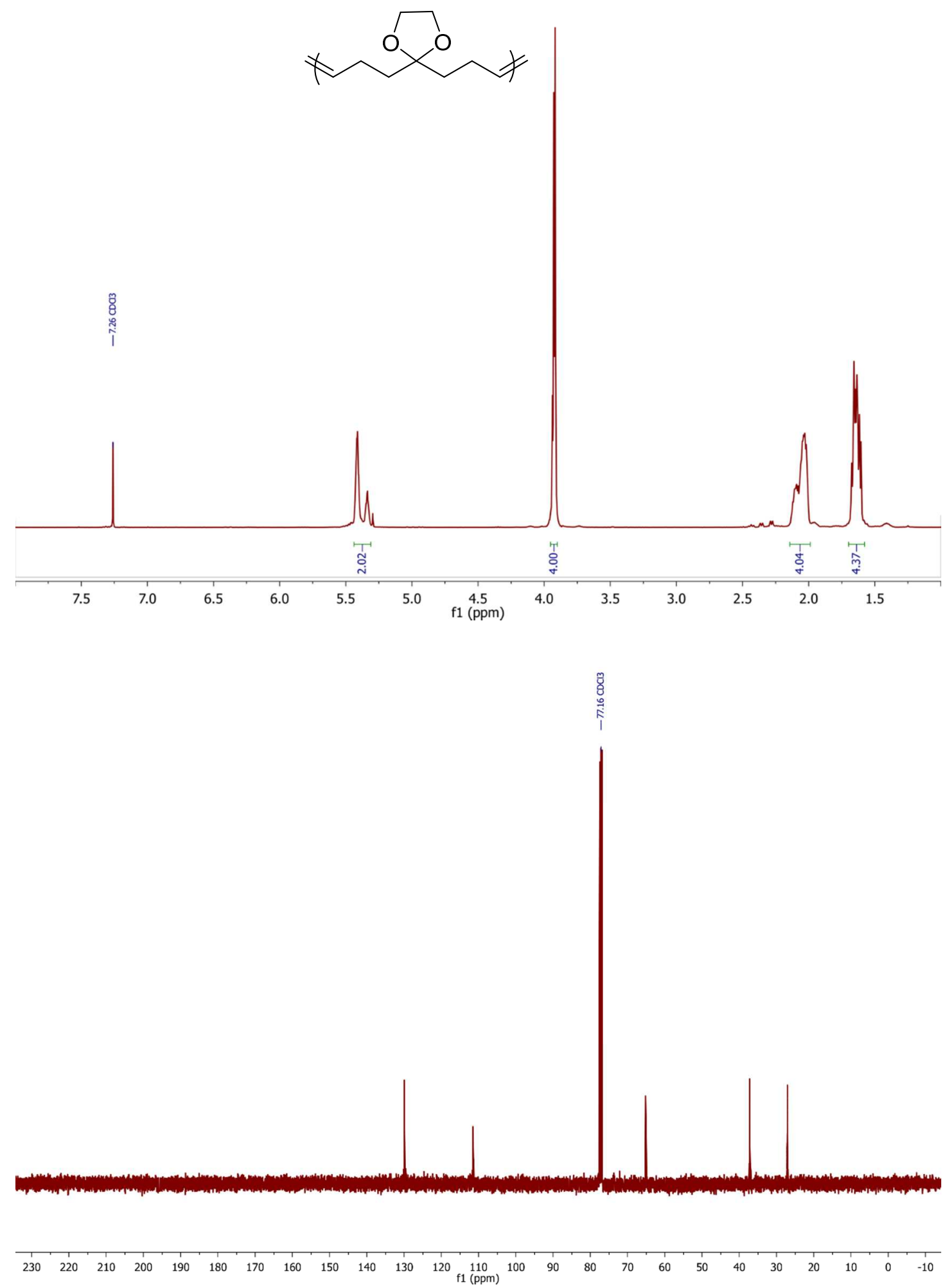

Figure S12: Polymer 7.5 NMR Spectra 

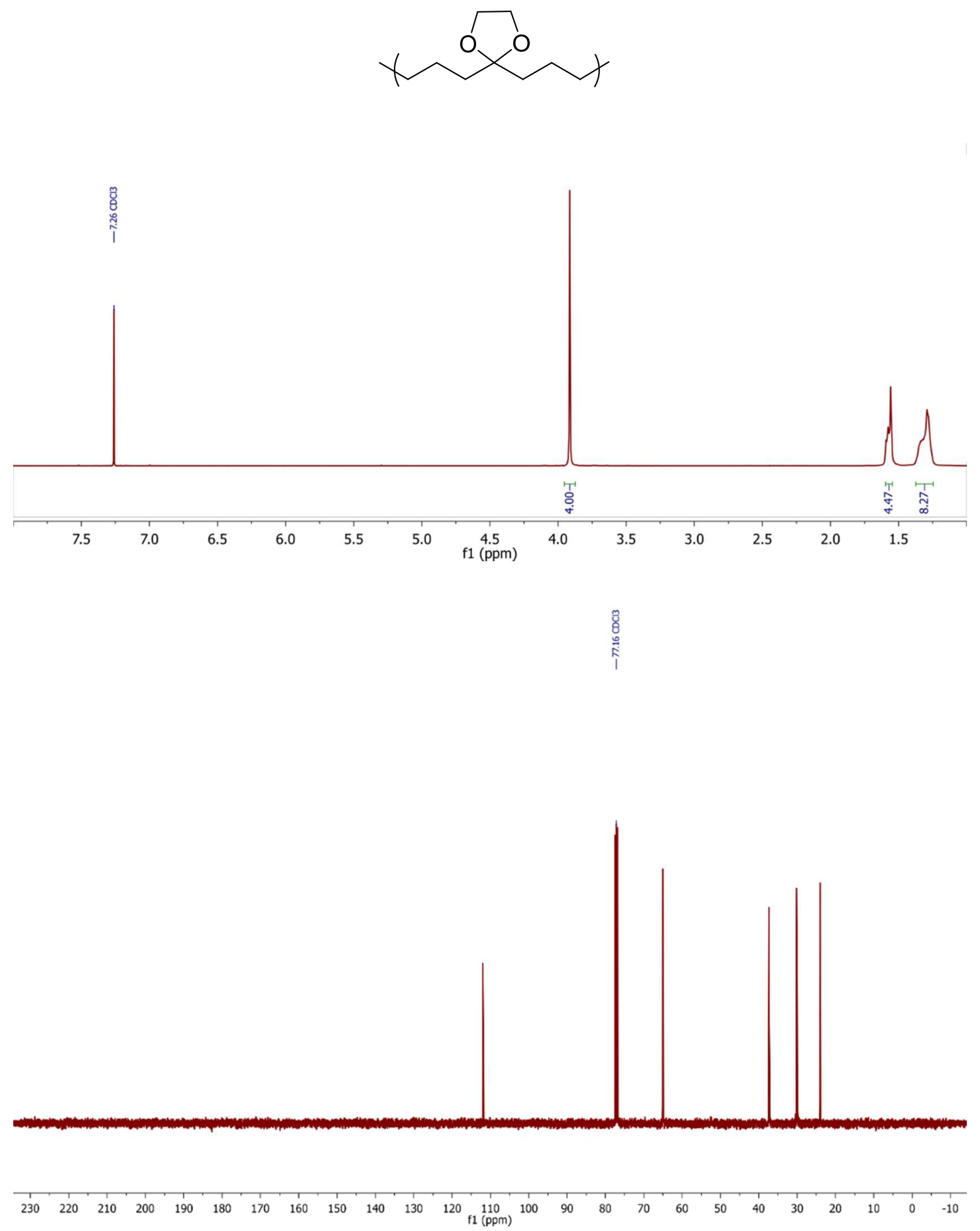

Figure S13: Polymer 7.6 NMR Spectra 

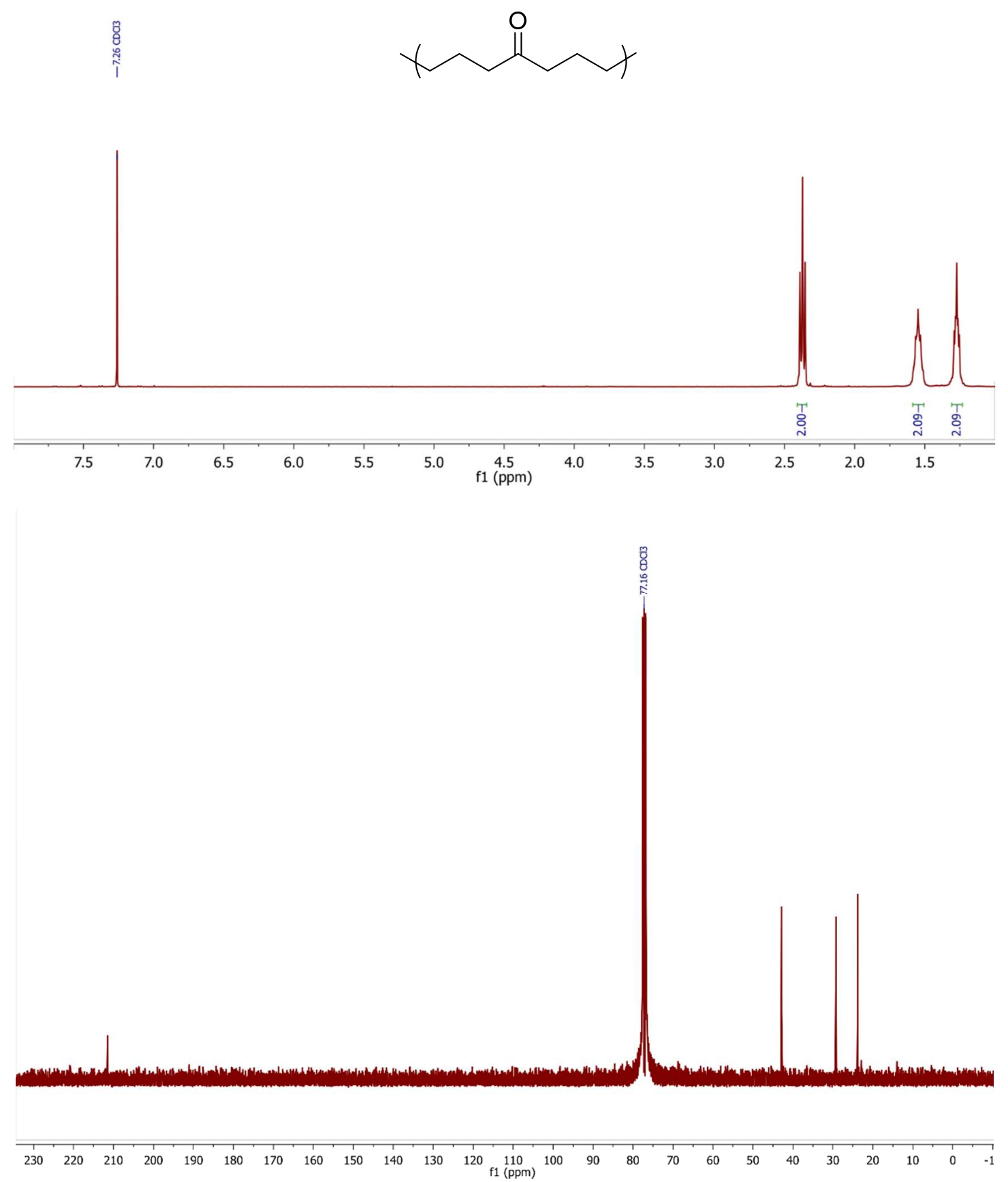

Figure S14: Polymer 7.7 NMR Spectra 


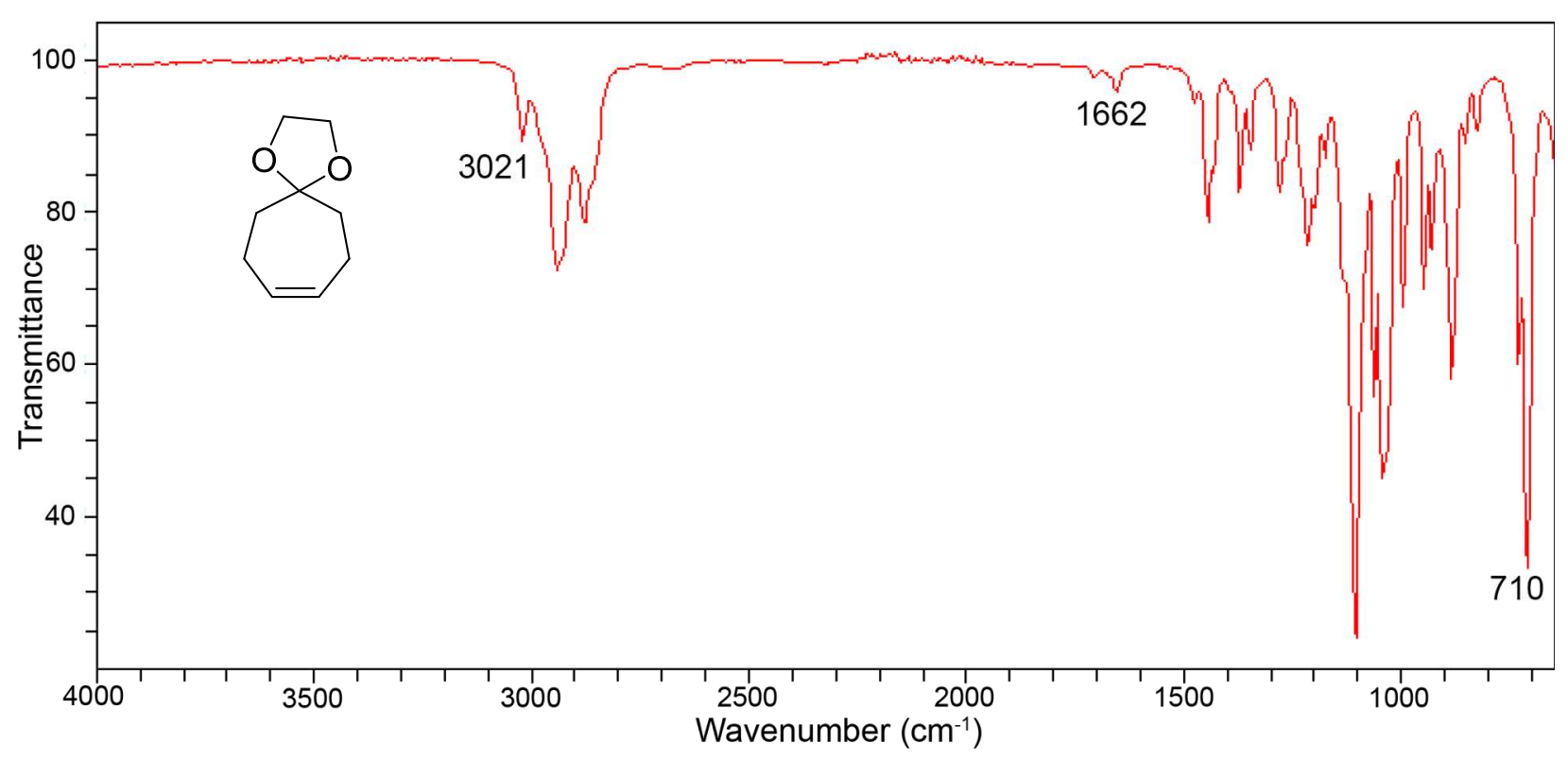

Figure S15: IR spectrum of monomer 7.4. The cis $\mathrm{C}=\mathrm{C}$ stretch appears at $1662 \mathrm{~cm}^{-1}$, and the cis vinyl C-H stretch and bend appear at $3021 \mathrm{~cm}^{-1}$ and $710 \mathrm{~cm}^{-1}$, respectively. These assignments are consistent with reported values. ${ }^{1}$

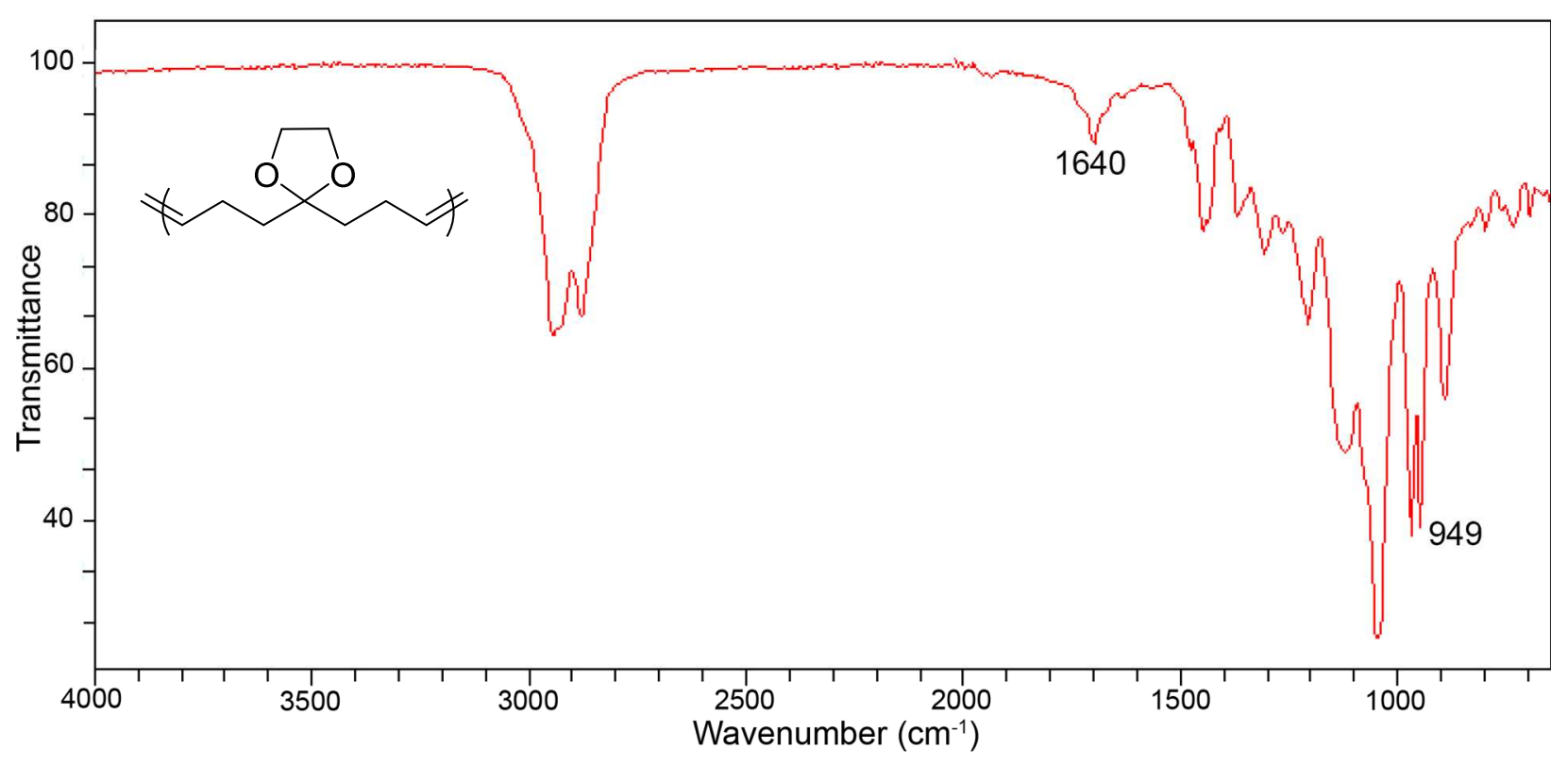

Figure S16: IR spectrum of polymer 7.5. The trans $\mathrm{C}=\mathrm{C}$ stretch appears at $1640 \mathrm{~cm}^{-1}$ while the trans $=\mathrm{C}-\mathrm{H}$ bend appears at $949 \mathrm{~cm}^{-1}$. These bands agree with accepted literature. ${ }^{1}$ 


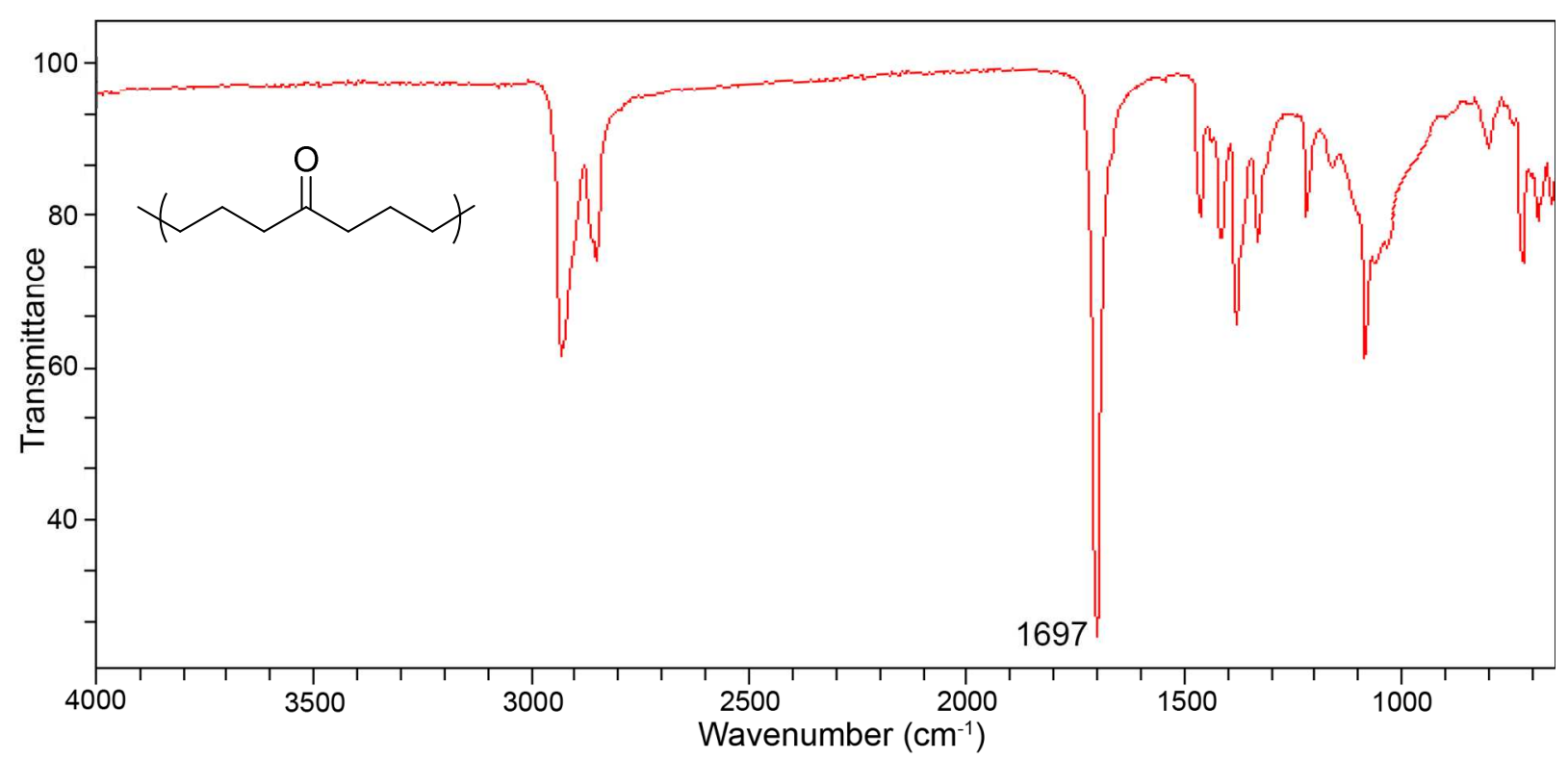

Figure S17: IR spectrum of polymer 7.7. The carbonyl C=O stretch appears at $1697 \mathrm{~cm}^{-1}$. These bands agree with accepted literature. ${ }^{1}$

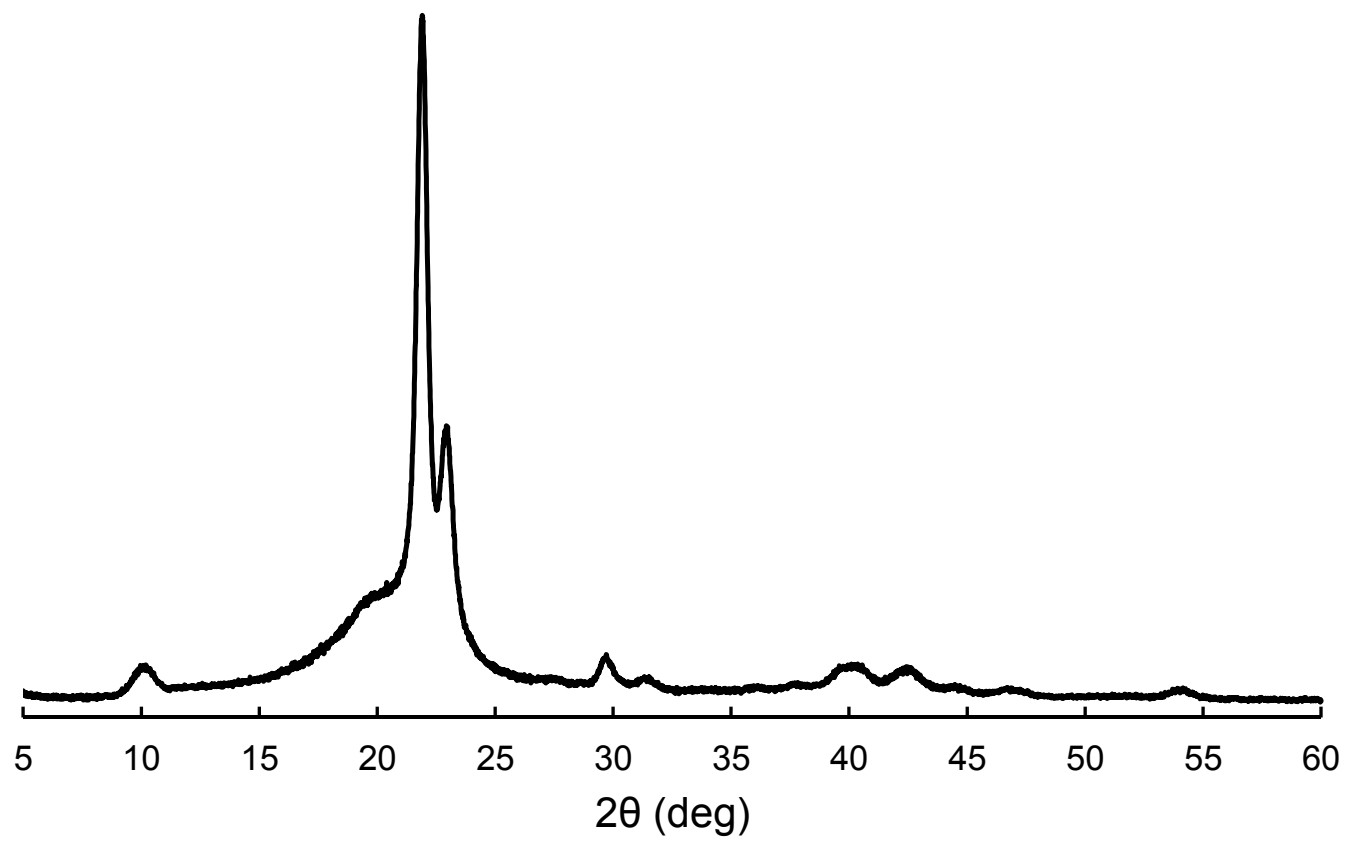

Figure S18: Wide-angle X-ray diffraction pattern of polymer $\mathbf{7 . 7}$ 

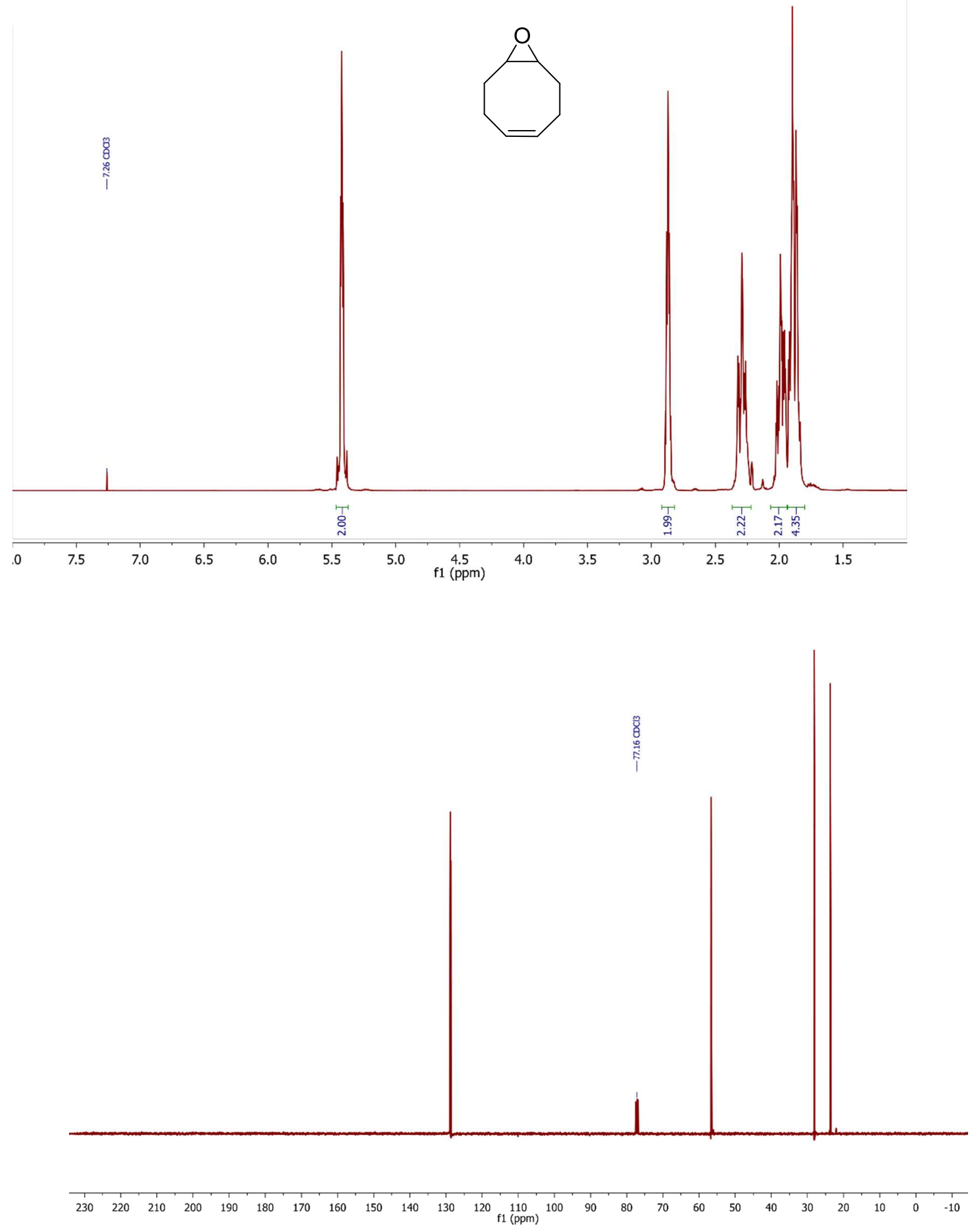

Figure S19: 8.1 NMR Spectra 

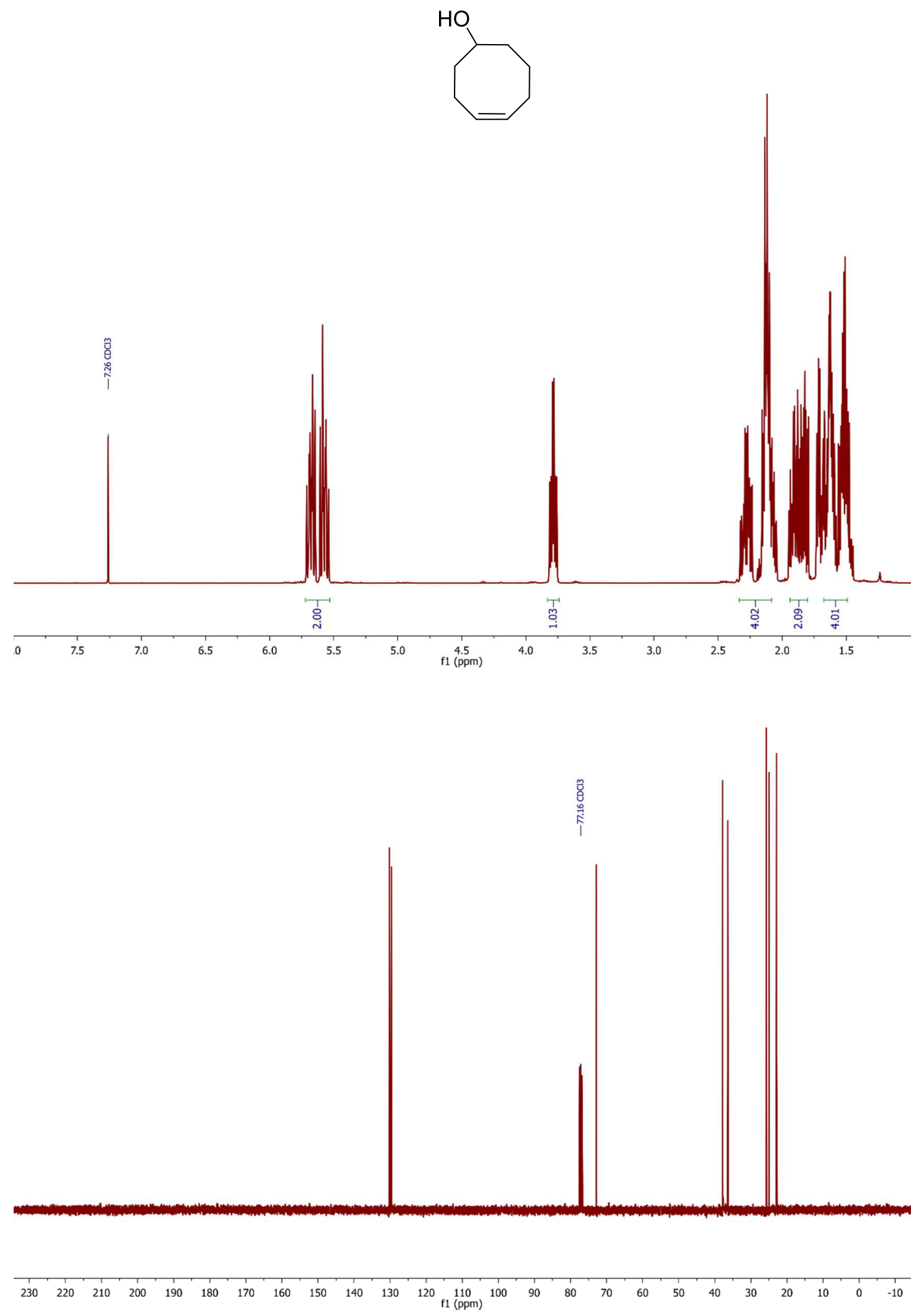

Figure S20: 8.2 NMR Spectra 

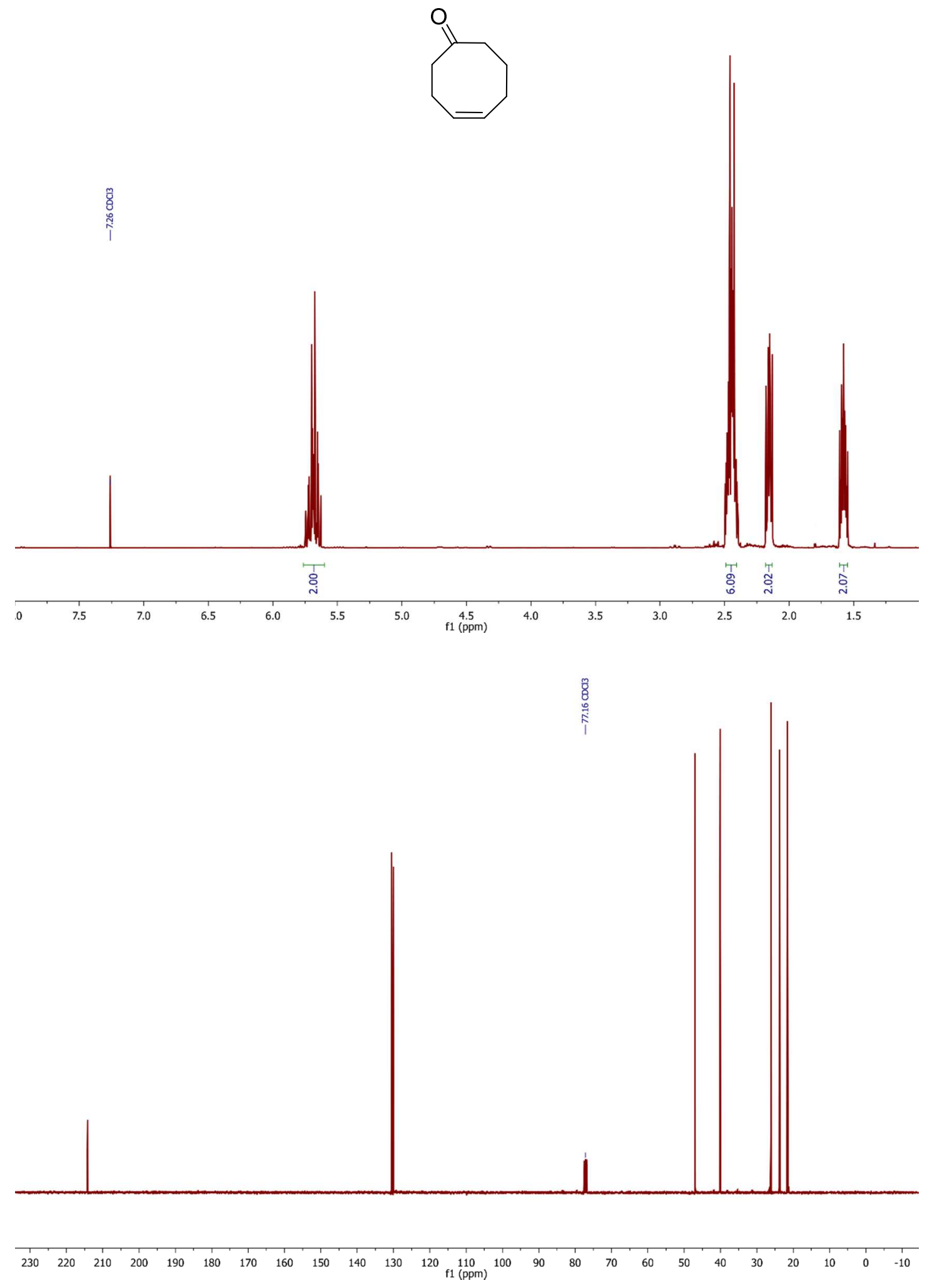

Figure S21: 8.3 NMR Spectra 

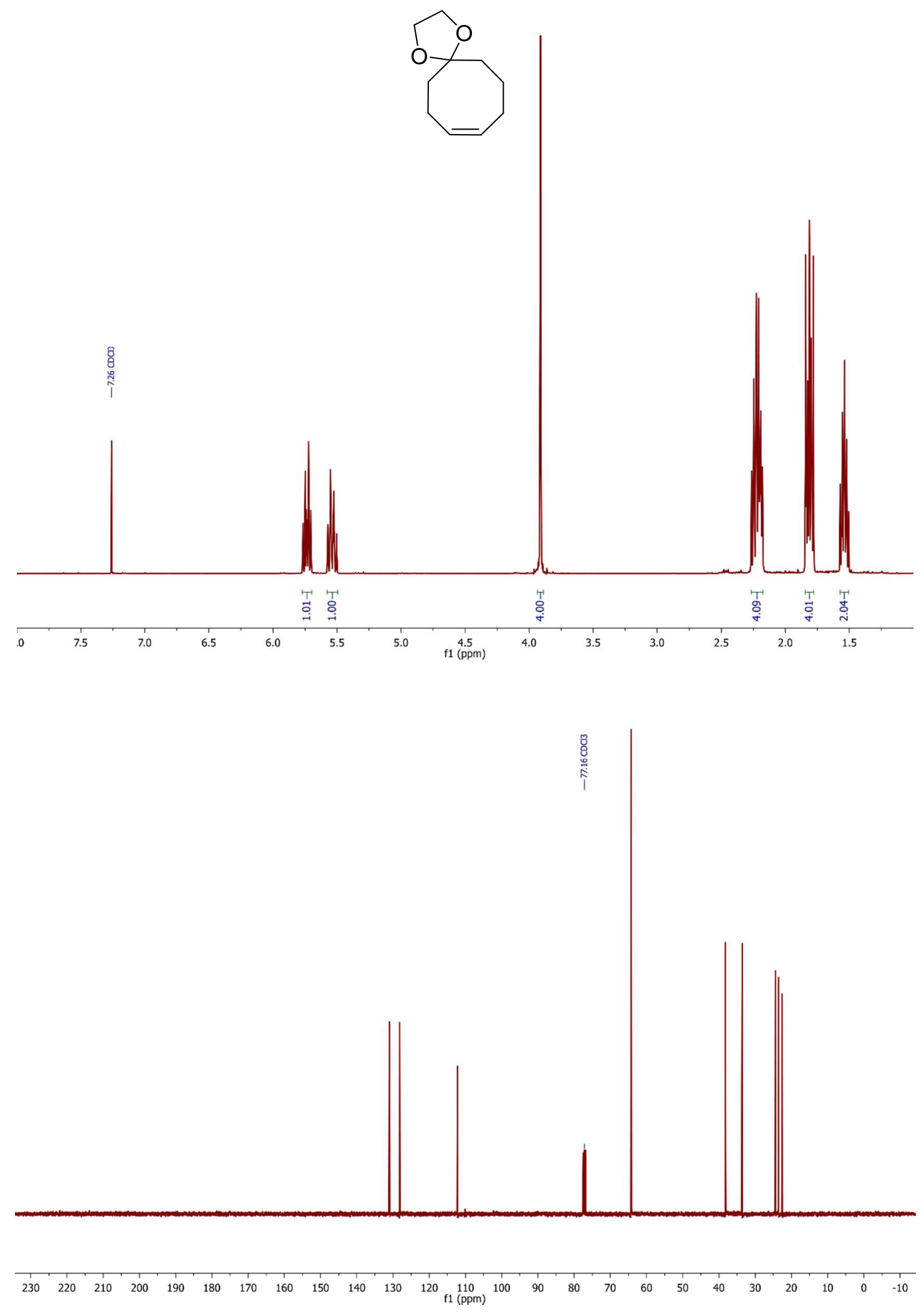

Figure S22: 8.4 NMR Spectra 

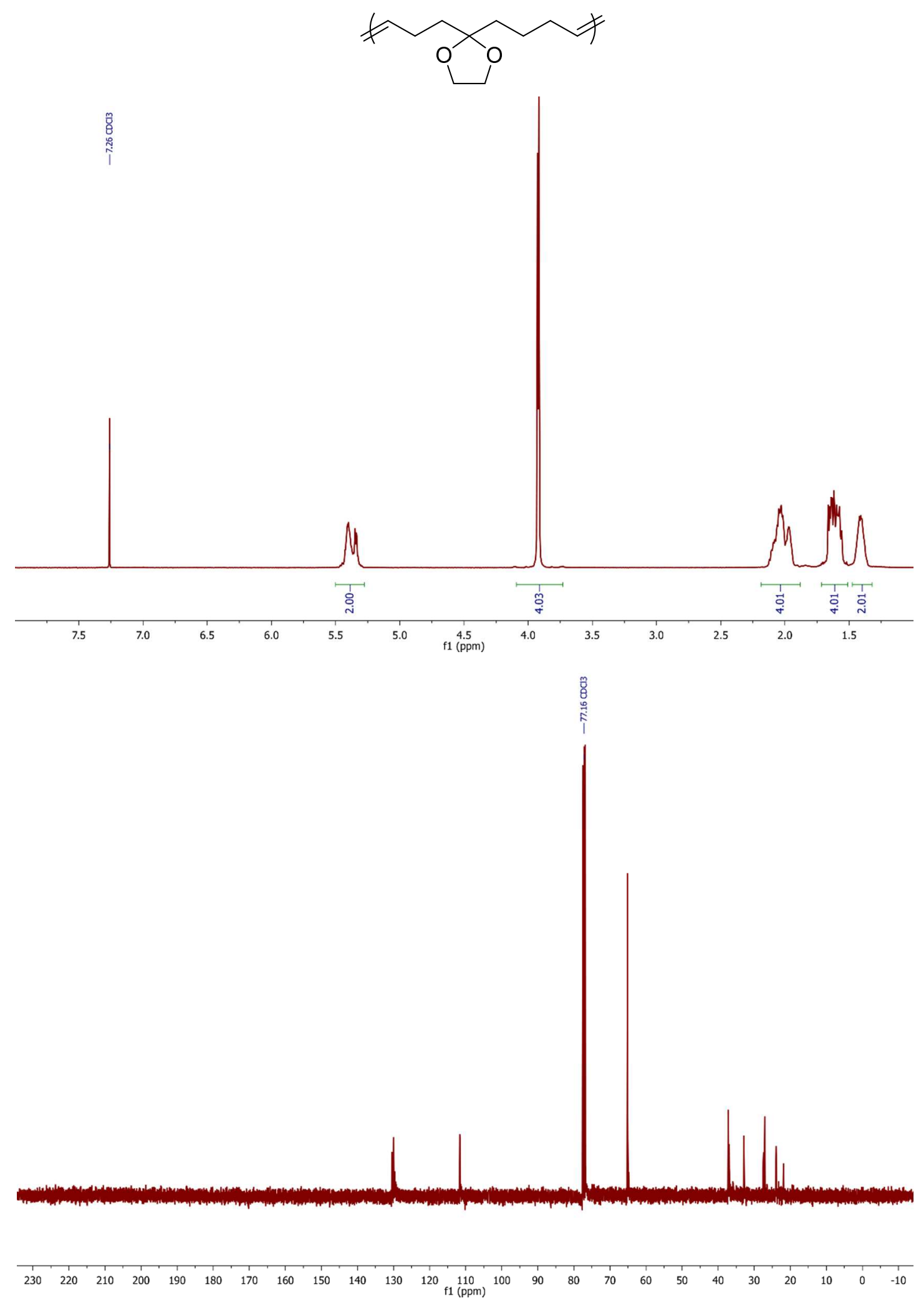

Figure S23: Polymer 8.5 NMR Spectra 

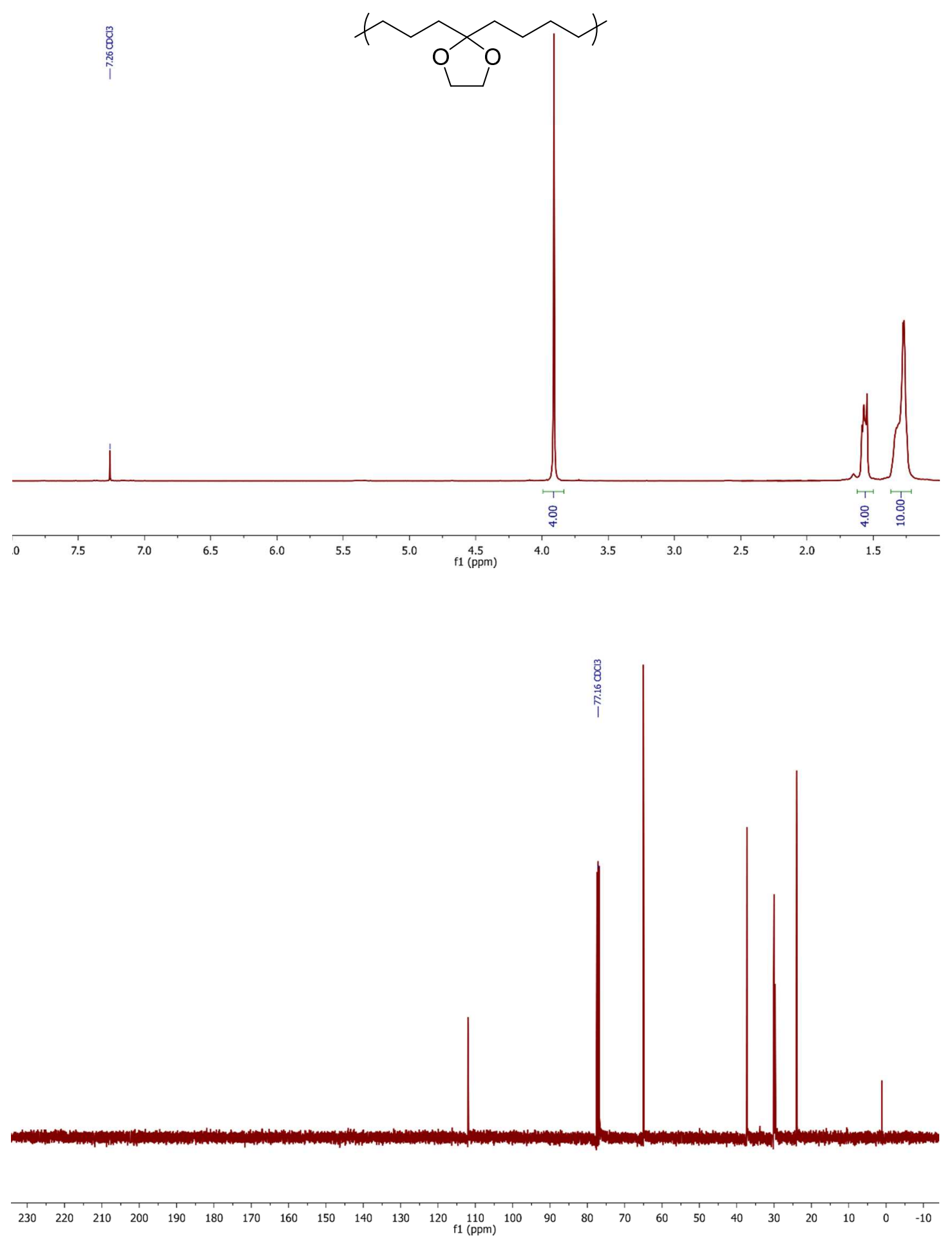

Figure S24: Polymer 8.6 NMR Spectra 


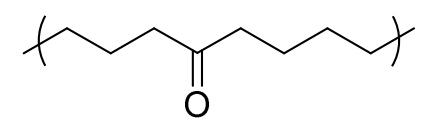
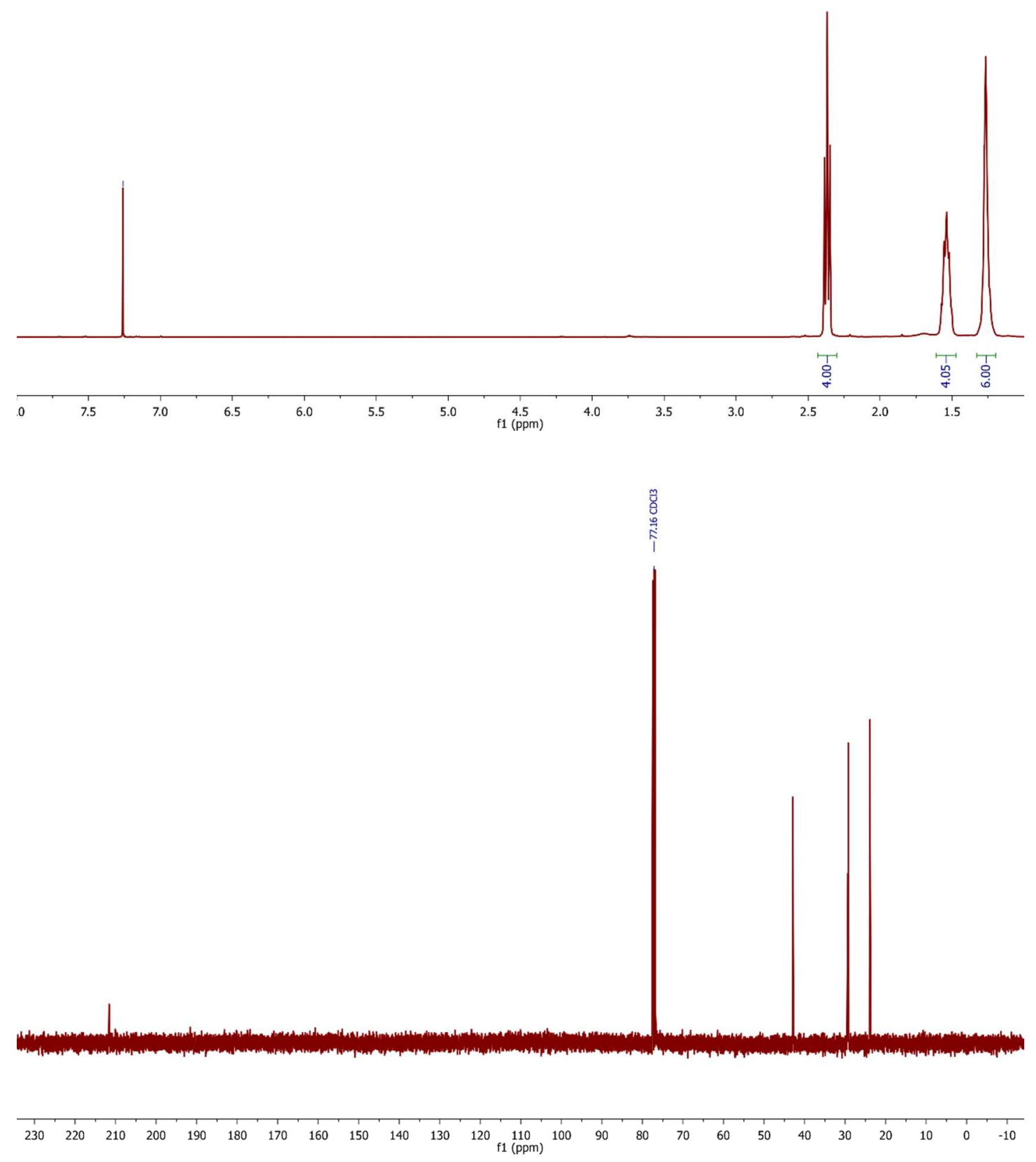

Figure S25: Polymer 8.7 NMR Spectra 


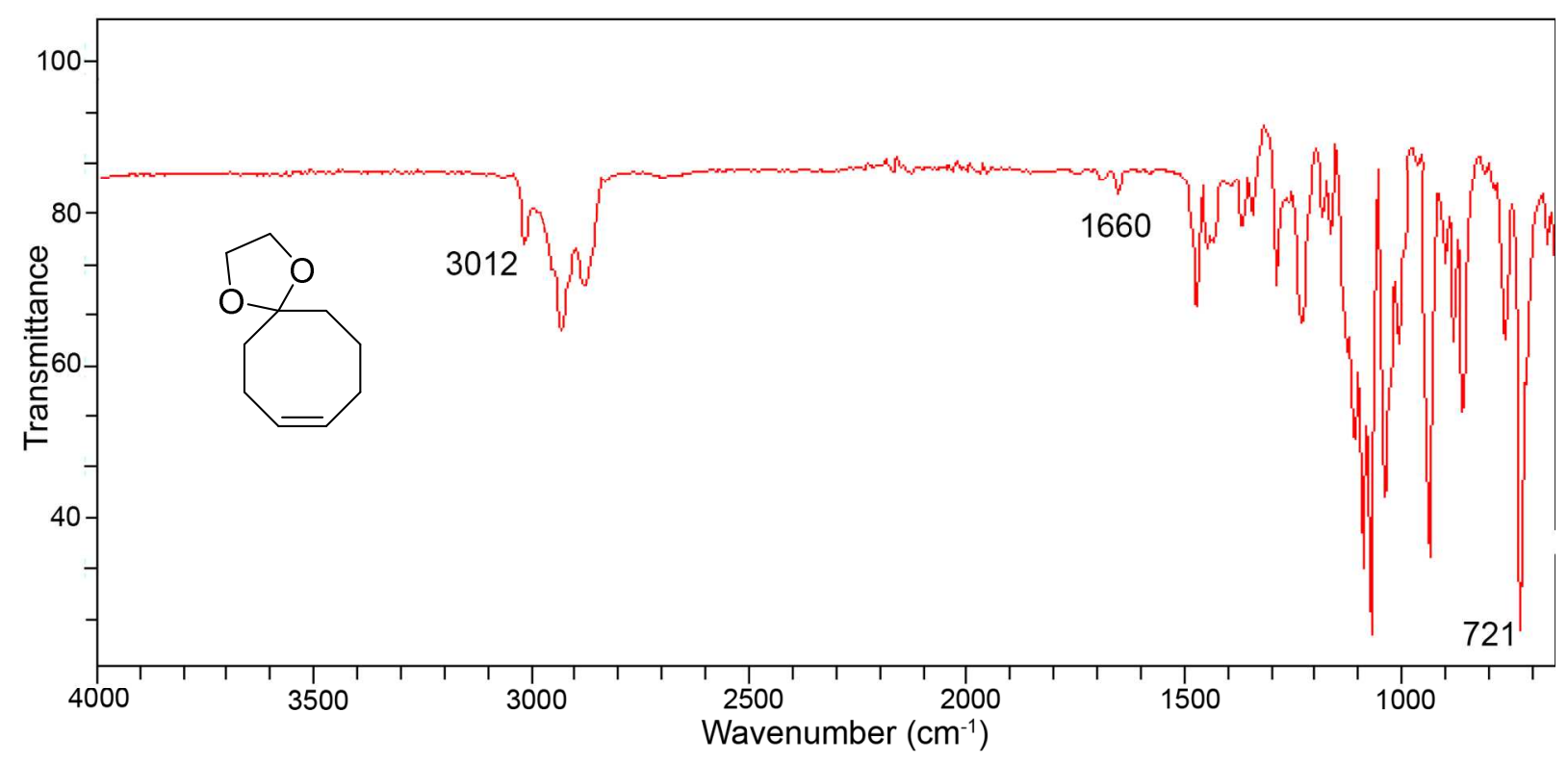

Figure S26: IR spectrum of monomer 8.4. The cis C=C stretch appears at $1660 \mathrm{~cm}^{-1}$, and the cis vinyl C-H stretch and bend appear at $3012 \mathrm{~cm}^{-1}$ and $721 \mathrm{~cm}^{-1}$, respectively. These assignments are consistent with reported values. ${ }^{1}$

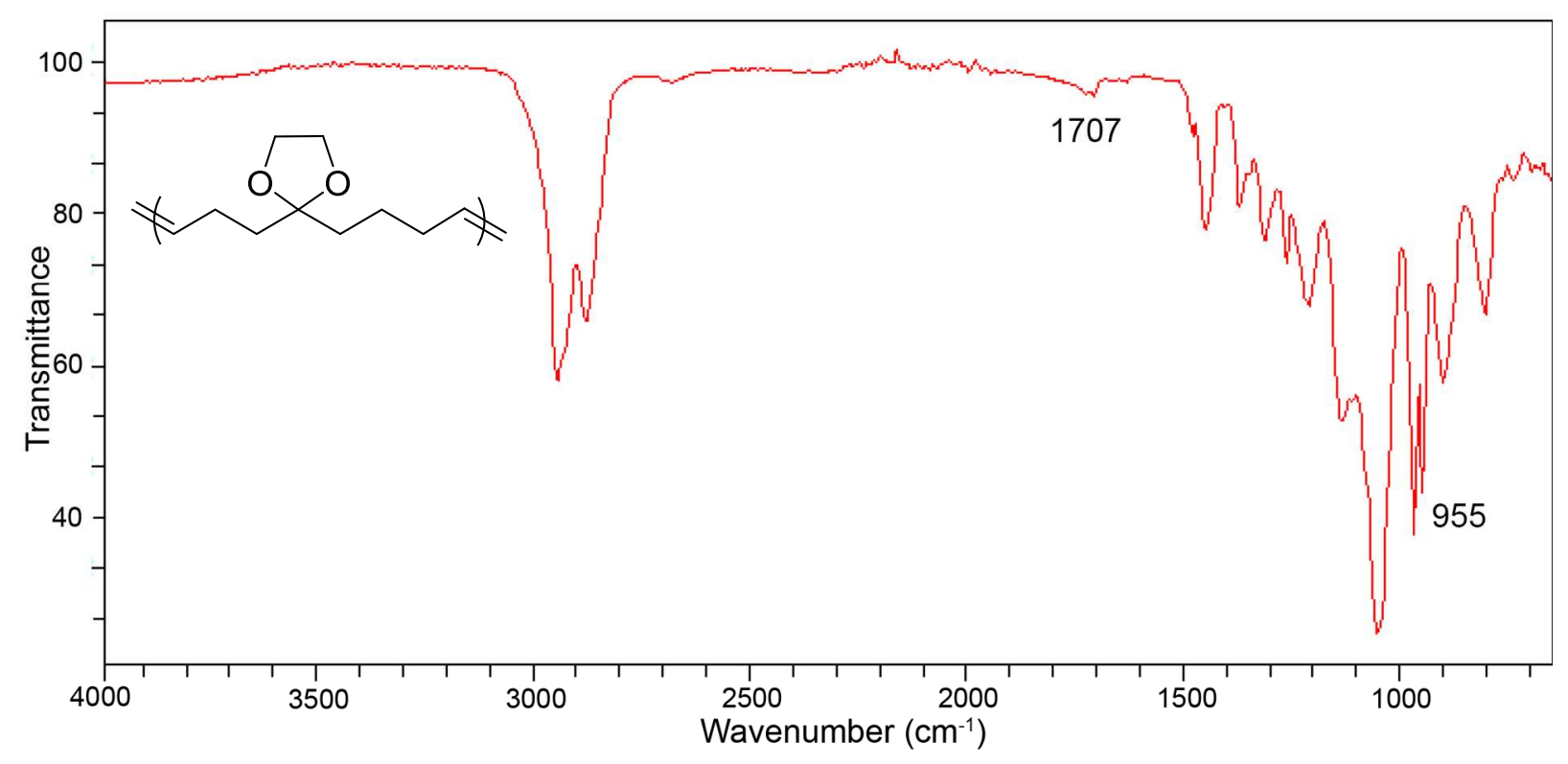

Figure S27: IR spectrum of polymer 8.5. The trans $\mathrm{C}=\mathrm{C}$ stretch appears at $1707 \mathrm{~cm}^{-1}$ while the trans $=\mathrm{C}-\mathrm{H}$ bend appears at $955 \mathrm{~cm}^{-1}$. These bands agree with accepted literature. ${ }^{1}$ 


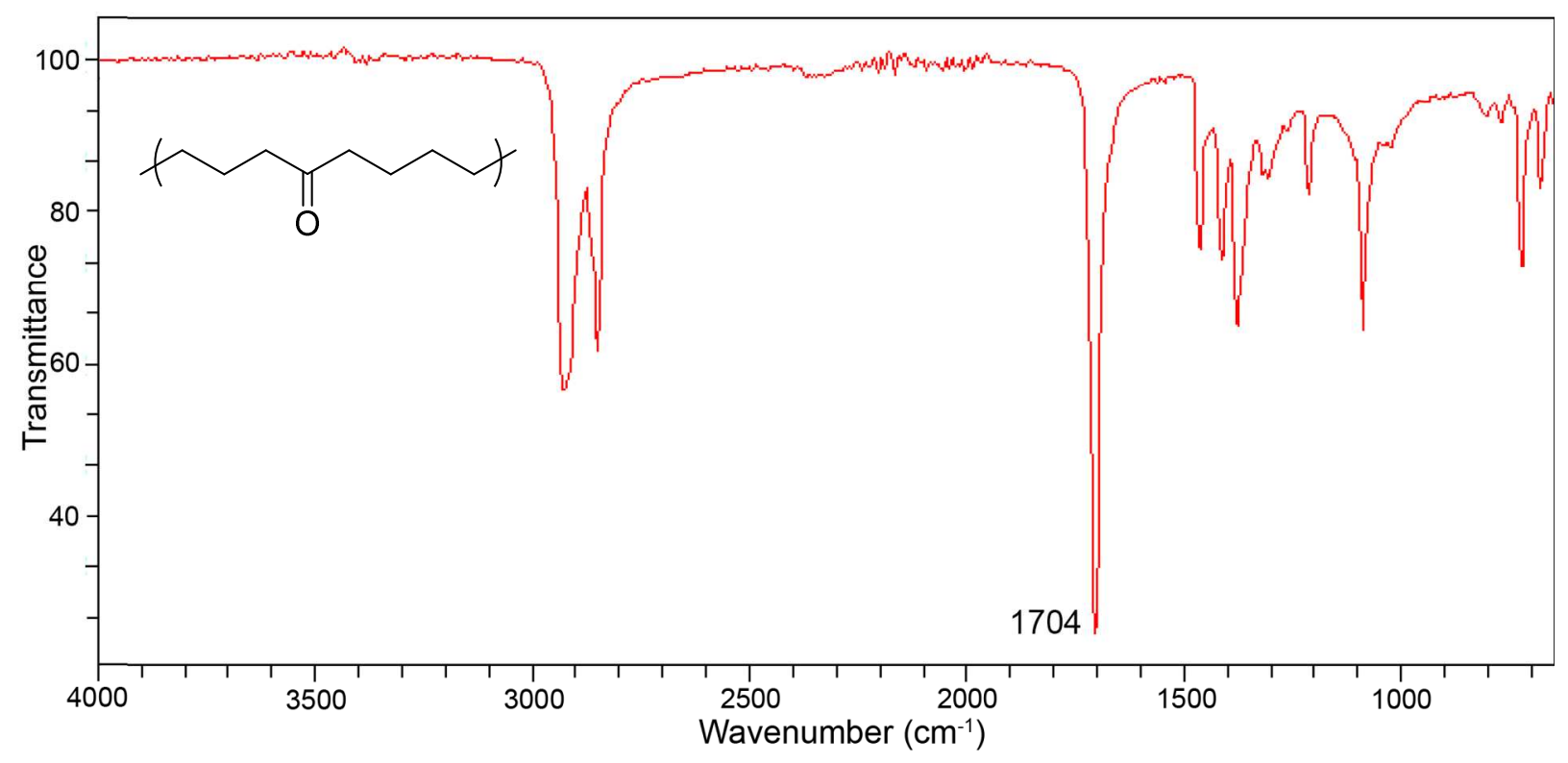

Figure S28: IR spectrum of polymer 8.7. The carbonyl C=O stretch appears at $1704 \mathrm{~cm}^{-1}$. These bands agree with accepted literature. ${ }^{1}$

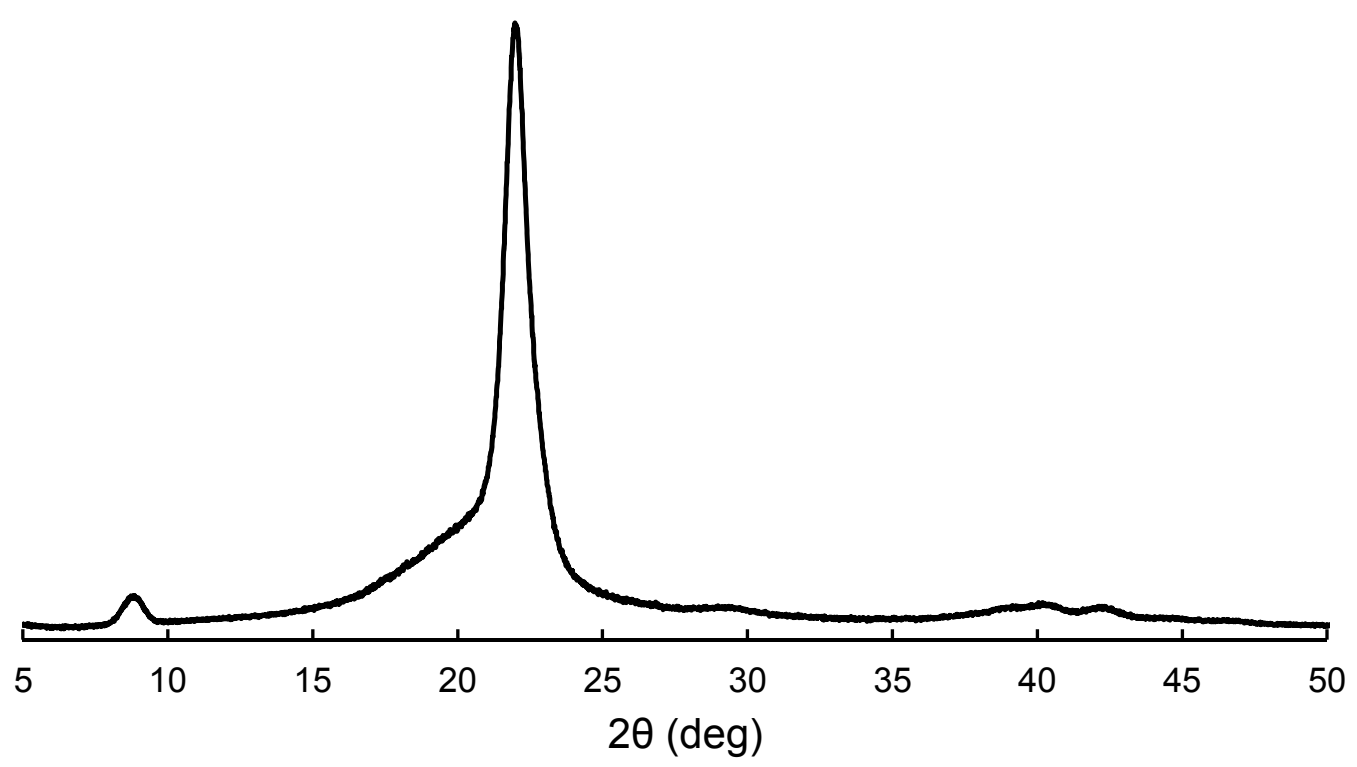

Figure S29: Wide-angle X-ray diffraction pattern of polymer $\mathbf{8 . 7 .}$

\section{References:}

1. Socrates, G., Infrared and Raman characteristic group frequencies: tables and charts. John Wiley \& Sons: 2004. 